\title{
Prison puzzle: treating hepatitis C
}

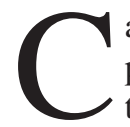

all it a quandary of epidemic proportions. Imagine a population group in which $30 \%$ of its members have a specific disease. It can be treated, but at a relatively stiff price that strains a limited budget. Along comes a new treatment that's much more effective but at threefold cost. Failure to effectively treat a patient will likely result in a long-term health condition that will constitute an even greater drain on resources. Complicating the task is that the political mandarins who ultimately fix the budget appear to be ideologically opposed to harm reduction programs that could reduce the incidence rate and treatment costs that appear to be rising exponentially.

That's precisely the dilemma and the scenario playing out in Canada's prisons as perplexed health providers scramble to treat an epidemic rate of hepatitis $\mathrm{C}$ infections.

According to figures obtained by $C M A J$ through a federal freedom of information request, Correctional Service of Canada's (CSC) bill for hepatitis drug treatment has increased almost sevenfold since 2005 to $\$ 4.7$ million in 2010 , roughly $4 \%$ of the agency's health budget for inmates.

A projected $30 \%$ of the 14900 inmates now housed in federal prisons are infected with hepatitis $\mathrm{C}$, which costs an estimated \$15 000-\$20000 to treat using a combination therapy containing peginterferon alfa- $2 \mathrm{~b}$ and ribavirin. But two new drugs, boceprevir and telaprevir, have come on the market that experts say are substantially more effective in treating hepatitis $\mathrm{C}$ in conjunction with traditional therapy, but will hike treatment costs to about $\$ 60000$ per patient.

Their use is now being evaluated by CSC officials and could easily triple the cost of treating hepatitis $\mathrm{C}$ within Canada's archipelago of 57 federal correctional facilities, says Dr. John Farley, a Vancouver, British Columbia-based physician.

The public health consequences of not providing treatment to inmates

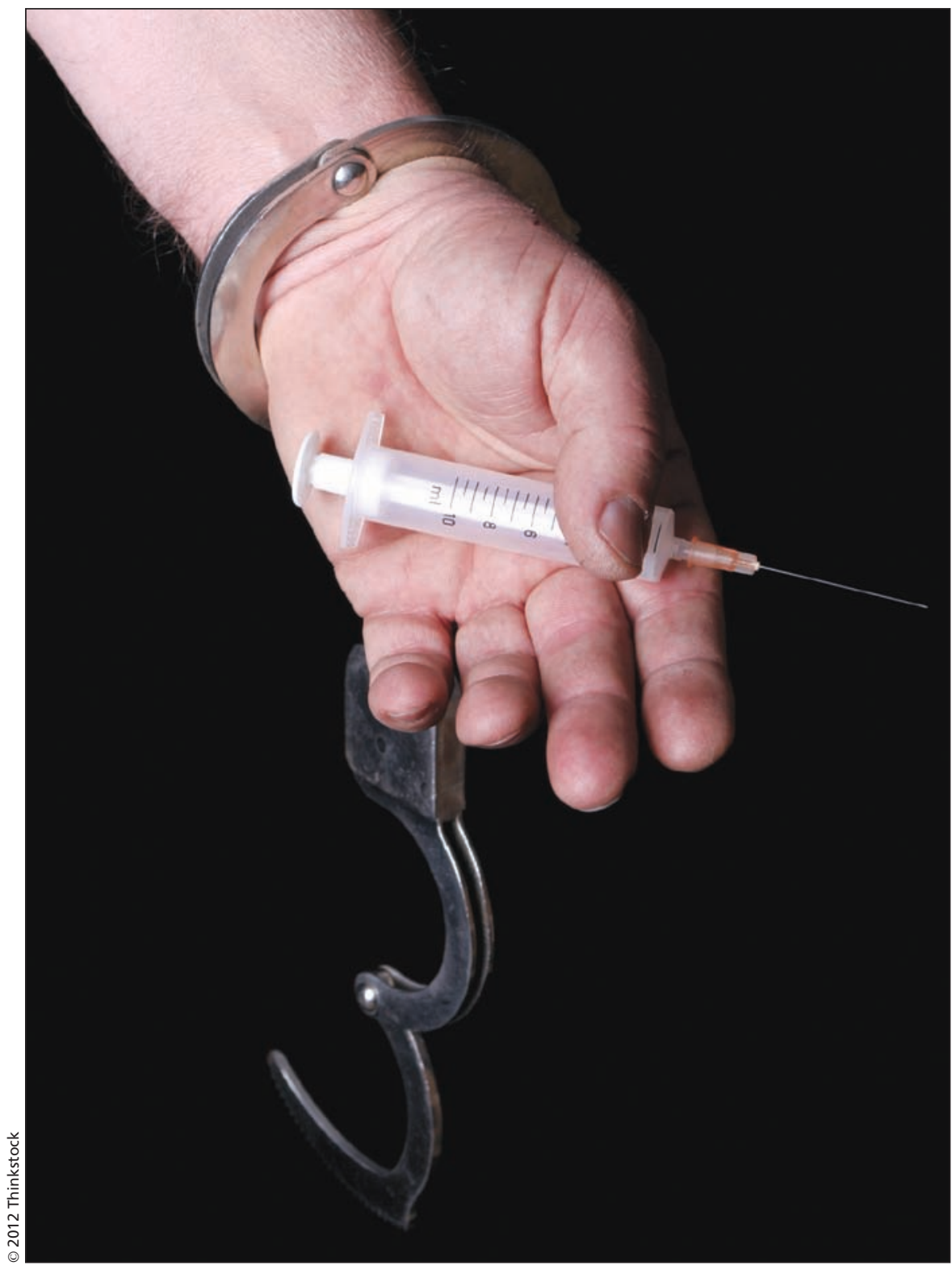

Two new drugs, boceprevir and telaprevir, have come on the market that experts say are substantially more effective in treating hepatitis $C$ in conjunction with traditional therapy, but they will apparently hike treatment costs to about $\$ 60000$ per inmate.

infected with hepatitis $\mathrm{C}$ are enormous, says Farley, noting that prisons serve as a major reservoir for a disease that infects an estimated 242000 Canadians. Untreated hepatitis invariably results in more infections within the general population, as well as a higher incidence rate of liver disease, which is even more costly to treat, he adds.
There's no question CSC has substantially ramped up its provision of treatment for hepatitis C, says Dr. Peter Ford, a Manitoulin Island, Ontario-based physician who oversees HIV and hepatitis treatment in federal prisons. "Just five years ago in some regions hardly anyone was getting treatment at all. There has been a dramatic increase in awareness of 
the treatment programs and growing numbers of inmates now seek treatment."

But demand continues to skyrocket and far outstrips treatment capacity.

In BC, "I now have almost 80 patients in treatment, with many more on my waiting list," says Farley.

Compounding the problem is that the federal government seems to find harm reduction programs in prisons to be anathema, the physicians say. CSC's "rejection of strategies such as needle exchange and safer tattooing programs in prisons is a well-known public health menace," Ford notes. "But the vastly increasing cost of HIV treatment in prisons proves that CSC's policies are financially irresponsible as well."

Farley says treating patients who became re-infected while in prison has become a nation-wide phenomenon. "We are now seeing many people being treated for hepatitis $\mathrm{C}$ at significant public expense and then getting reinfected because of the government's rejection of basic harm reduction measures. The financial cost of hepatitis $\mathrm{C}$ in the prisons is becoming horrific."

Both physicians abhor the federal government's dismantling of a pilot project aimed at promoting safer tattooing within six federal prisons in 2006. An estimated $45 \%$ of inmates receive unsterile tattoos (www.cmaj.ca/lookup /doi/10.1503/cmaj.1070017), while an estimated $25 \%$ of inmates use needles to inject illegal substances (QJM 2000; 93:113-19).

Some of the latter are first-time users, Farley says. "I usually ask my patients where they started injecting drugs and between 5 and 10 percent say it was while in prison."

Harm reduction programs in federal prisons are now essentially limited to such "half-measures" as providing bleach to sterilize needles, Farley says. Yet, "bleach is known to be an ineffective way of preventing disease transmission."

Failure to implement adequate harm reduction measures, lack of adequate access to care and lack of consistency between federal institutions lay at the heart of a failing grade that CSC received in 2011 from the Canadian Coalition of Organizations Responding to Hepatitis B and $\mathrm{C}$ (www.canadianhepatitiscoalition .ca/wp-content/uploads/2011/07/2011 -Hepatitis-Strategy-Report-Card.pdf)

"We gave them an $\mathrm{F}$ because we have to believe that CSC is fully aware that people engage in risky behaviour in prison," says coalition spokeswoman Deb Shmitz. "It's a denial of the reality not to provide full harm reduction. Just as there is a duty to treat inmates with hepatitis, there is a similar duty to do harm reduction as well. And that includes distributing needles and collecting used needles."

Shmitz argues CSC should be held partially responsible for the rising rate of hepatitis $\mathrm{C}$ infection in non-inmate population groups as it's fully aware inmates typically join the ranks of intravenous drug users and the homeless when they are released into the general population. "The public needs to know that failure to prevent hepatitis transmission inflicts a severe long-term financial burden on public health systems."

For its part, CSC argues that its approach is working. The hepatitis $\mathrm{C}$ prevalence rate appears to be "levelling" at about $30 \%$, says Dr. Linda Panaro, public health medical advisor for CSC, ascribing that to the efficacy of treatment programs and harm reduction measures such as bleach provision. "The harm reductions materials we distribute are having an effect."

Panaro adds that the sevenfold increase in hepatitis $C$ treatment costs within prisons is the product of more rigorous cost accounting measures but acknowledges those costs may skyrocket if the new therapies are approved for use. - Paul Christopher Webster, Toronto, Ont.

CMAJ 2012. DOI:10.1503/cmaj.109-4191

\section{Medical ink}

I f your spouse's initials are "D.N.R.," you should probably think twice before tattooing them on your chest. Then again, if your end-of-life plans include a do-not-resuscitate order, maybe it's not such a bad idea after all.

It appears the tattoo craze has expanded beyond mere aesthetics into medicine. Some people are setting down advance directives on skin in addition to paper. Others are opting for tattoos on their wrists instead of Medic Alert bracelets, favouring ink over jewellery. Though there are advantages to turning your epidermis into a medical record - you can't accidently leave your forearm at home - some health professionals fear that paramedics and emergency physicians might not notice the tattoos, let alone treat them as proper instructions.

"Emergency responders understand the concept of MedicAlert bracelets and they look for them on the wrist. It is possible that some have learned that people are using tattoos but the chances of them looking for it are much less," says Robert Ridge, president and CEO of the Canadian MedicAlert Foundation. "There is no overriding body that governs emergency services in Canada, so when something changes there is no national means to communicate it. Getting every emergency responder to look for something new can be a challenge."
The days of tattoos being associated only with bikers and ex-cons are long gone. Now tattooing is firmly planted in the mainstream. A woman is as likely to have one as a man. There are reality television shows about tattoo artists. Celebrities sport tattoos, including the popular actress Angelina Jolie, who has nearly a dozen. Many professional athletes are covered in more ink than an incontinent squid.

In the United States, $36 \%$ of people in the 18-25 age bracket have a tattoo, and that percentage increases to $40 \%$ for people between the ages of 25 and 40, according to the Pew Research Center in Washington, DC (http://pewresearch .org/databank/dailynumber/?NumberID 